\title{
"Effect of body measurements on first lactation length in Jersey crosses and Holstein Friesian crosses"
}

\author{
*Rajeev Mishra ${ }^{1}$, Ram Pal Singh ${ }^{2}$, Sarvjeet Herbert ${ }^{3}$ \\ Department of Animal Husbandry \& Dairying Sam Higginbottom University of Agriculture, Technology \& \\ Sciences Allahabad-211007, U. P. \\ *Corresponding Author: Rajeev Mishra
}

\begin{abstract}
A study was conducted to predict the influence of body measurements on first lactation length of Jersey crosses and Holstein Friesian crosses. Body weight, body height, heart girth, body length and posterior girth measurements were taken from 50 Jersey crosses and $70 \mathrm{HF}$ crosses. Experimental animals were fed \& managed under tail to tail system of housing at dairy farm. From the calculation of data on different parameters it is concluded that body weight, heart girth, body height, Posterior girth of Jersey crosses had no effect on lactation length whereas body length had significant effect on lactation length while heart girth, body height, Posterior girth had no effect on lactation length and body weight, body length had significant effect on lactation length in $\mathrm{HF}$ crosses.
\end{abstract}

Keywords: Cattle, body measurements, body weight, Holstein Friesian, Jersey crosses, lactation length.

\section{Introduction}

Farmers in general, select animals on the basis of type, because correct and complete production records are not available except on very few organized dairy farms. Therefore the type of conformation occupies an important part in evaluation of the animal. The significance of this is relatively more in cows and buffaloes because body weight, heart girth and height at withers are the common parameters reported to have some correlation with the milk production (Singh and Prasad, 1983). Such study may furnish some useful information that may help relation with the milk production in predicting the productive ability thereby improving the milking herd. From the very beginning animal breeders have tried to establish a close relationship between external characteristics and milk production so that selection of dairy animals become possible. It is commonly ascribed that udder is the most vital part for forecasting the yield of milk in dairy animals. So far selection of a dairy cow, body and mammary development is given a great importance.

\section{Material and methods}

This study were carried out in the herd maintained in the Department of Animal Husbandry and Dairying, SHUATS, Allahabad During the period of 2012-2015 of 50 Jersey crosses and 70 HF crosses. Body weight of animals was determined by using a digital weighing scale. The parameters such as body weight, heart girth, body height, body length and posterior girth were measured using measuring and tape when animals were standing as described in The best prediction equations for body weight from other traits (heart girth, body height, body length and posterior girth) as independent variables were determined. The animals were professionally managed and kept under similar management conditions. The animal received adequate ration and greens throughout the year. The data on various factors and parameters were collected, tabulated and subjected to analysis of variance technique (ANOVA) as per Snedecor and Cochran (1994).

\section{Results and Discussion}

Table. 1 presents results concerning the effect of the body measurements on first lactation length of the Jersey crosses and Holstein-Friesian crosses. Statistical analysis showed that the body length had a highly significant effect on first lactation length of Jersey crosses and in HF crosses body weight had a significant effect on lactation length similar results were also reported by Bereskin and Touchberry (1967). The body weight groups' of the body length first lactation length in Jersey and H.F. crosses ranged from 270-603 days and 281-506 days, respectively. The mean first lactation length in Jersey of crosses for different body weight groups were 354.50 days, 393.56 days, and 372.13 days and in HF crosses were 326.92 days, 321.70 days, and 390.94 days, respectively. The differences in first lactation length in Jersey crosses due to different body weight groups were non-significant (Table 1). In HF crosses significant (Table 1) respectively. Similar results are also in agreement with Csomos (1965). 
"Effect of body measurements on first lactation length in Jersey crosses and Holstein Friesian ...

Table: 1 Effect of body measurement on first lactation length in Jersey and Holstein Friesian crosses

\begin{tabular}{|c|c|c|c|c|}
\hline \multirow{4}{*}{$\begin{array}{l}\text { Parameters } \\
\text { Body weight (kg) }\end{array}$} & \multicolumn{2}{|c|}{ Jersey crosses (liter/lactation) } & \multicolumn{2}{|c|}{ Holstein Friesian crosses (liter/lactation) } \\
\hline & BW1(255-282) & 354.50 & BW1(236-292) & 326.92 \\
\hline & BW2(283-309) & 395.56 & BW2(293-349) & 321.70 \\
\hline & BW3(310-336) & 372.13 & BW3(350-406) & 390.94 \\
\hline \multirow[t]{3}{*}{ Heart girth (inch) } & HG1(5.10-5.56) & 327.60 & HG1(5.40-6.10) & 356.38 \\
\hline & HG2(5.68-6.25) & 386.55 & HG2(6.20-6.70) & 325.97 \\
\hline & HG3(6.26-6.81) & $369 . .63$ & HG3(6.80-7.60) & 338.91 \\
\hline \multirow[t]{3}{*}{ Body length (inch) } & BL1(5.10-5.44) & 426.90 & BL1(5.20-5.60) & 334.76 \\
\hline & BL2(5.45-5.78) & 379.18 & BL2(5.70-6.20) & 334.71 \\
\hline & BL3(5.79-6.12) & 337.92 & BL3(6.30-6.90) & 350.44 \\
\hline \multirow[t]{3}{*}{ Body height (inch) } & BH1(4.10-4.70) & 413.50 & BH1(4.10-5.00) & 349.36 \\
\hline & $\mathrm{BH} 2(4.80-5.30)$ & 377.90 & $\mathrm{BH} 2(5.10-5.90)$ & 327.27 \\
\hline & $\mathrm{BH} 3(5.40-5.90)$ & 368.10 & BH3(6.00-6.99) & 355.63 \\
\hline \multirow[t]{3}{*}{ Posterior girth (inch) } & PG1(5.10-5.64) & 393.48 & PG1(5.10-6.00) & 337.63 \\
\hline & PG2(5.65-6.18) & 361.72 & PG2(6.10-6.80) & 344.29 \\
\hline & PG3(6.19-6.79) & 410.00 & PG3(6.90-7.70) & 334.38 \\
\hline
\end{tabular}

The heart girth group's for first lactation length in Jersey and H.F. crosses ranged from 270-603 days and 281-506 days, respectively. The mean first lactation length in Jersey crosses for different heart girth groups were 327.60 days, 386.55 days, and 369.63 days and in HF crosses were 356.38 days, 325.97 days, and 338.91 days, respectively. The difference in first lactation length in Jersey crosses due to different heart girth groups were non-significant (Table. 1) and also in HF crosses (Table. 1) respectively. Similar results are also in agreement The body length group' for first lactation length in Jersey crosses and H.F. ranged from 270-603 days and 281-506 days, respectively. The mean first lactation length in Jersey crosses for different body length groups were 426.90 days, 379.18 days, and 337.92 days and in HF crosses were 334.76 days, 334.71 days, and 350.44 days, respectively. The difference in first lactation length in Jersey crosses due to different body length groups were significant (Table. 1) and same result were also obtained in HF crosses (Table. 1) respectively. Similar results are also in agreement with The body height groups' for first lactation length in Jersey and H.F. ranged from 270-603 days and 281-506 days, respectively. The mean first lactation length in Jersey crosses for different body height groups were 413.50 days, 377.90 days, and 368.10 days and in HF crosses were 349.36 days, 327.27 days, and 355.63 days, respectively. The difference in first lactation length in Jersey crosses due to different body height groups were non-significant (Table. 1) and in HF crosses (Table. 1) respectively. Similar results are also in agreement with and Acharya (1989). The Posterior girth groups first lactation milk yield in Jersey and H.F. crosses ranged from 270-603 days and 281-506 days, respectively. The mean first lactation length in Jersey crosses for different posterior girth groups were 393.48 days, 361.72 days, and 410.00 days and in HF crosses were 337.62 days, 344.29 days, and 334.38 days, respectively. The difference in first lactation length same findings were in Jersey crosses due to different Posterior girth groups were non-significant (Table. 1) and in HF crosses (Table. 1) respectively.

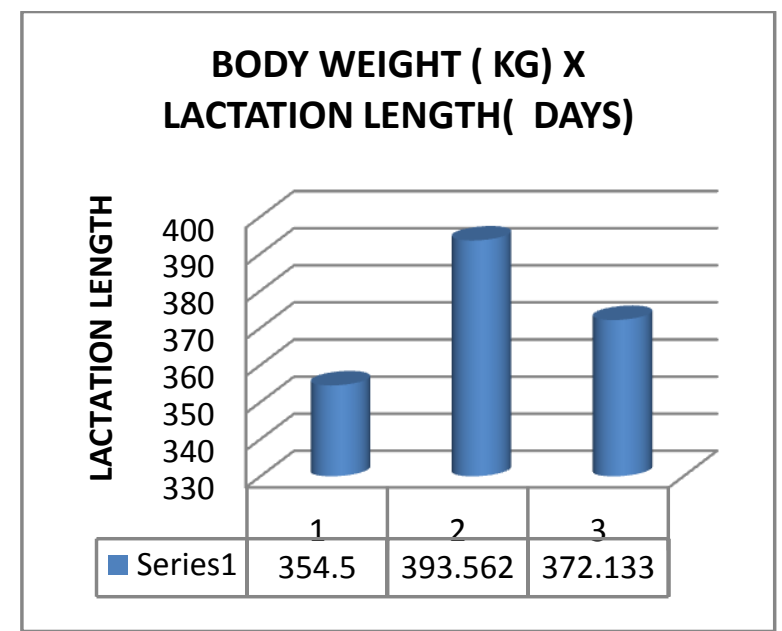

FIG 1: First lactation lactation length in Jersey crosses due to body weight. 


\section{HEART GIRTH X LACTATION LENGTH} (DAYS)

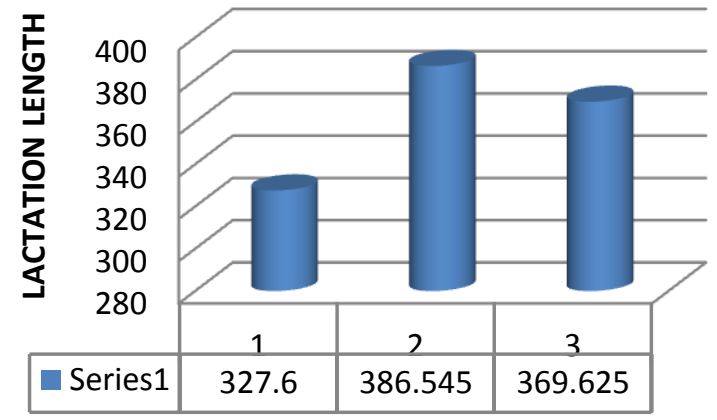

FIG 2: First lactation lactation length in Jersey crosses due to heart girth.

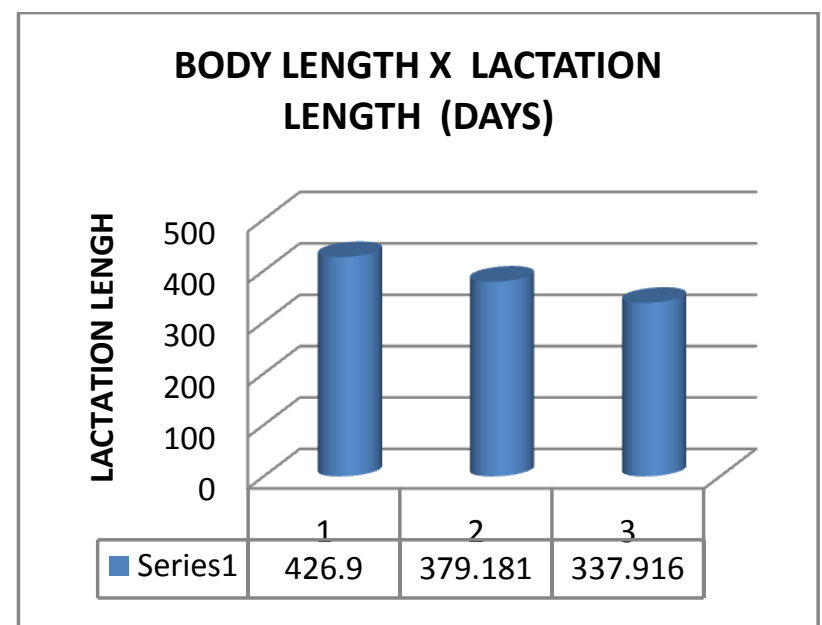

FIG 3: First lactation lactation length in Jersey crosses due to body length.

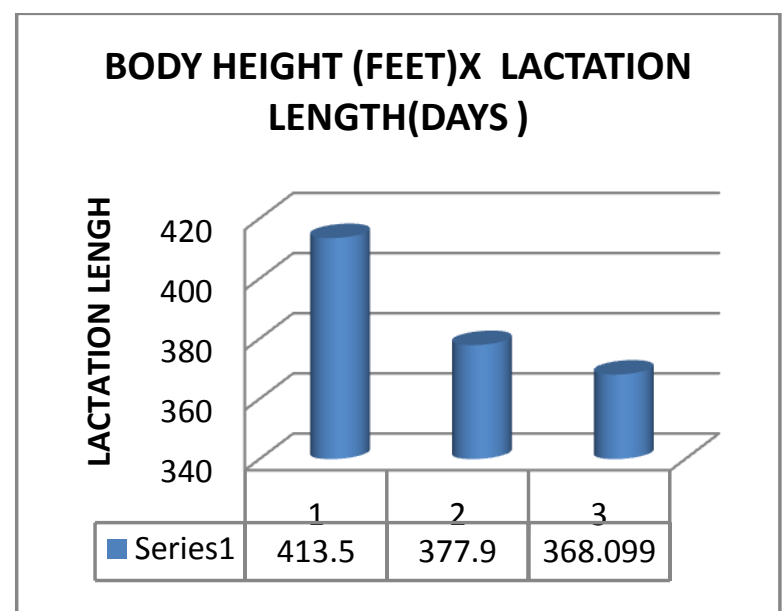

FIG 4: First lactation lactation length in Jersey crosses due to body height. 


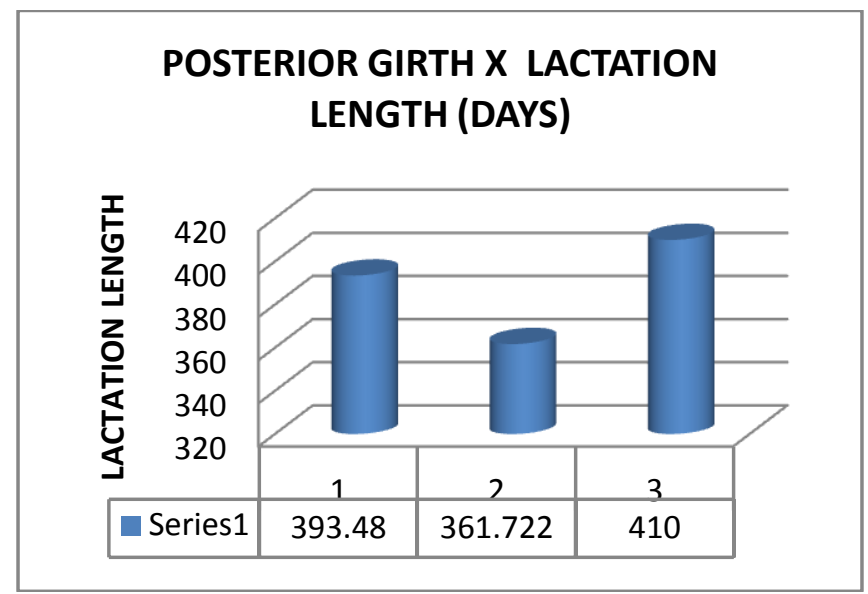

FIG: 5: First lactation lactation length in Jersey crosses due to posterior girth.

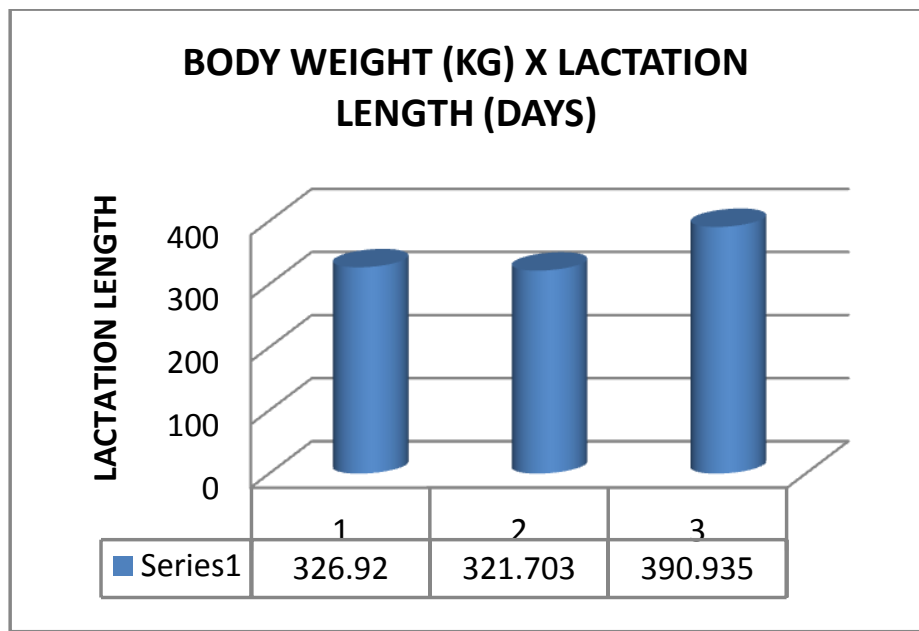

FIG: 6: First lactation lactation length in HF crosses due to body weight.

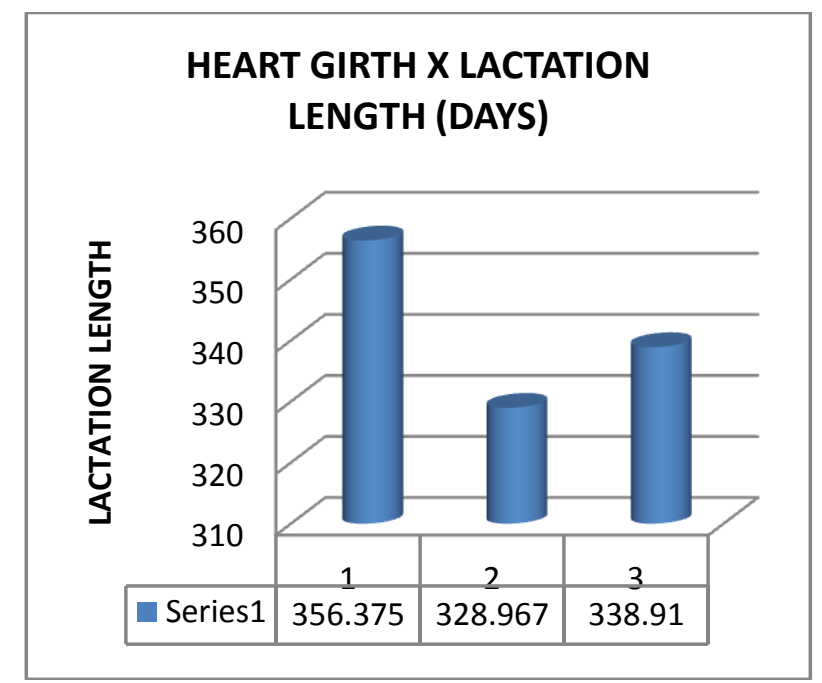

FIG: 7: First lactation lactation length in HF crosses due to heart girth. 


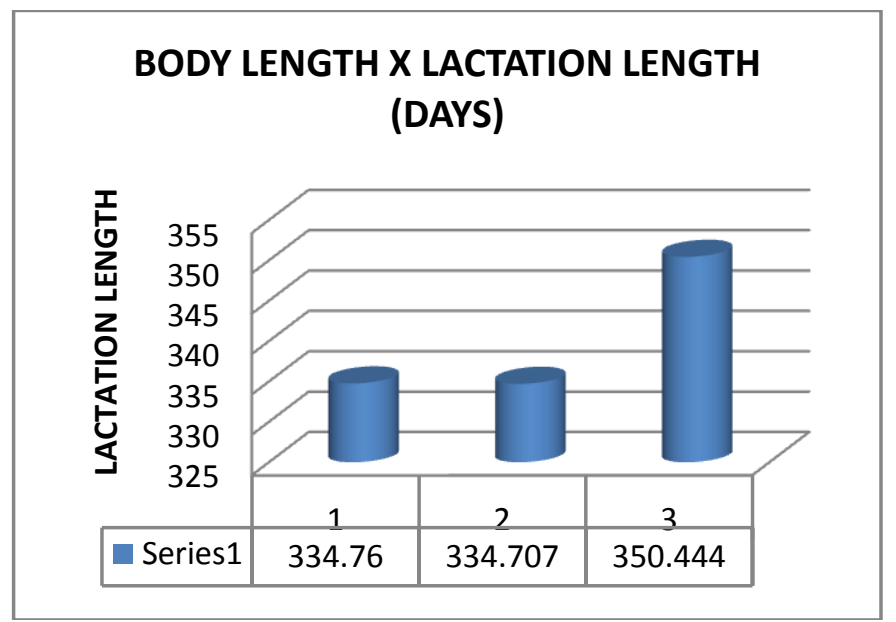

FIG: 8: First lactation lactation length in HF crosses due to body length.

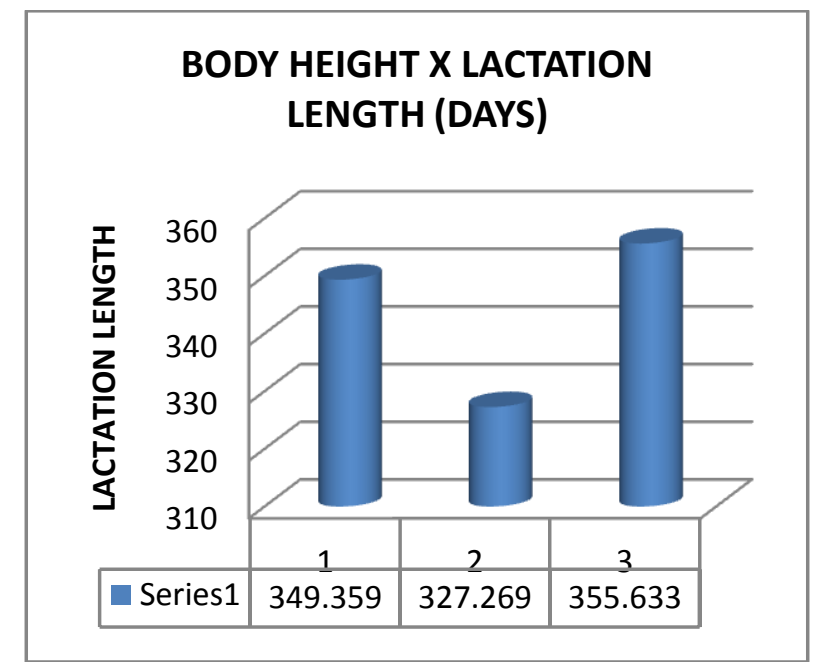

FIG: 9: First lactation lactation length in HF crosses due to body height.

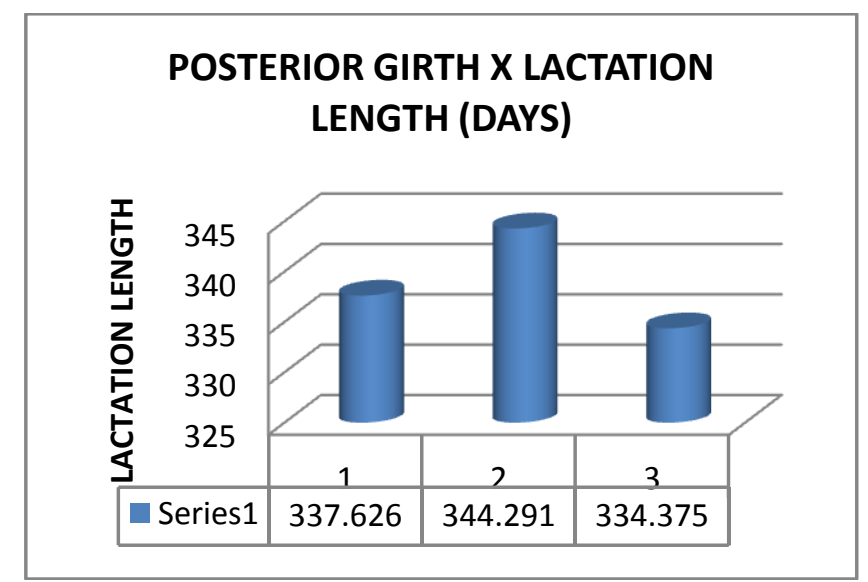

FIG: 10: First lactation lactation length in HF crosses due to posterior girth

\section{Conclusion}

It is concluded that the body measurement has significant effect on first lactation length of body length and non significant effect of body weight, heart girth, body height and posterior girth in Jersey crosses. In Holstein Friesian crosses had significant effect of body weight and non significant effect of heart girth, body length, body height and posterior girth on first lactation length. Therefore, these factors can be taken into consideration while selecting animals for better production or for breeding improvement. 


\section{References}

[1]. Acharya, R. M. (1989). "Cattle cross breeding to increase milk production. An instrument of rural development". A success story in india ,personal communication.

[2]. Bereskin , B. and Touchberry, R. W. (1967). some relationship of body weight and first lactation yield. Animal Breeding Abs., 35 (1), 49.

[3]. Csomos, Z. (1965). The relation between body weight and lactation yield in Hungarian spotted cows. Animal Breeding Abs., 33 (4), 544.

[4]. Sarkar, G and Prasad, J. (1997). "Effect of lactation length and service period on economic traits of HF crosses ( $\left.\mathrm{F}_{1}\right)$ underagroclimatic conditions of West Bengal." M.Sc. Thesis A.A.I. Allahabad.

[5]. Snedecor GW and Cochran W.G. (1994) Statistical method $8^{\text {th }}$ edition the Iowa State University. Press Amer Iowa USA.

[6]. Singh, S. P. and Prasad, J. (1983). To study the correlation of certain body measurements, age at first calving and body weight at different age with total milk yield and butter fat production in Murrah buffaloes and Red sindhi cows, Dairy Sci. Abstr. 45(7) No. 4458. The Livestock Advisor 8(2), 47-49.

Rajeev Mishra. "'Effect of body measurements on first lactation length in Jersey crosses and Holstein Friesian crosses"." IOSR Journal of Agriculture and Veterinary Science (IOSR-JAVS) 10.7 (2017): 71-76. 